\title{
Lip squamous cell carcinoma in a Brazilian population: Epidemiological study and clinicopathological associations
}

\author{
Ludmilla-Regina Souza ${ }^{1}$, Thiago Fonseca-Fonseca ${ }^{1}$, Carolina-Carvalho Oliveira-Santos ${ }^{1}$, Gefter-Thiago-Ba- \\ tista Corrêa ${ }^{1}$, Francis-Balduíno-Guimarães Santos ${ }^{2}$, Cláudio-Marcelo Cardoso ${ }^{2}$, Desiree Sant'Ana-Haikal ${ }^{2}$, \\ André-Luís-Sena Guimarães ${ }^{3}$, Alfredo-Maurício-Batista De Paula ${ }^{3}$

\footnotetext{
${ }^{1}$ Postgraduate. Health Science Programme. State University of Montes Claros, Montes Claros, Brazil

${ }^{2}$ Lecturer. DDS. Department of Dentistry and Medicine. State University of Montes Claros, Montes Claros, Brazil

${ }^{3}$ Lecturer. DDS. PhD. Health Science Programme. Department of Dentistry. State University of Montes Claros, Montes Claros, Brazil
}

Correspondence:

Laboratório de Pesquisa em Saúde.

Hospital Universitário Clemente de Faria.

Universidad Estadual de Montes Claros - Unimontes.

Av. Cula Mangabeira, 562- Bairro Santo Expedito.

Montes Claros - Minas Gerais - Brazil.

CEP: 39401-001.

ambpatologi@gmail.com

\begin{abstract}
Souza LR, Fonseca-Fonseca T, Oliveira-Santos CC, Corrêa GTB, Santos FBG, Cardoso CM, Sant'Ana-Haikal D, Guimarães ALS, De Paula AMB. Lip squamous cell carcinoma in a Brazilian population: Epidemiological study and clinicopathological associations. Med Oral Patol Oral Cir Bucal. 2011 Sep 1;16 (6):e757-62.

http://www.medicinaoral.com/medoralfree01/v16i6/medoralv16i6p757.pdf
\end{abstract}

Received: 06/03/2010

Accepted: $26 / 08 / 2010$

\begin{abstract}
Objectives: It was evaluated epidemiological aspects of primary lip squamous cell carcinoma (LSCC) and its associations with clinicopathological factors. Study design: This retrospective, cross-sectional study analysed a sociodemographic, clinical, and morphological data of HNSCC in a Brazilian population $(n=30)$. Data analysis included descriptive statistics and bivariate analyses using the chi-square and Fisher's exact tests to compare the variables. Results: The LSCC represented $10.8 \%$ of all oral cavity squamous cell carcinoma. Lip malignant disease was more prevalent in elderly men, with male-to-female ratio of 5:1. Lower lip was more affected. It was observed high rates of chronic solar exposure, and tobacco and alcohol drinking habits. Clinically, early TNM staging, small tumour lesions, and non-metastatic disease were predominant findings. It was identified a high frequency of well differentiated tumor samples. Worse Karnofsky performance status was associated with cervical metastasis. Conclusions: Our findings showed that LSCC patients exhibited similar epidemiological and clinical profiles as noted in other studies. Still, the occurrence of metastatic disease was associated with a worse physical performance status of the LSCC patients during diagnosis.
\end{abstract}

Key words: Squamous cell carcinoma; lip; epidemiology, clinical factors. 


\section{Introduction}

Lip squamous cell carcinoma (LSCC) is a common oral malignancy, and it is responsible for over $30 \%$ of all oral squamous cell carcinomas $(1,2)$. LSCC occurs in the lower lip about $80 \%$ of all cases and results mainly from chronic exposition to ultraviolet (UV) component of the solar radiation, especially UVB (1,3-5). Main factors associated with disease development are outdoor activities and skin colour. However, socio-demographic and lifestyle factors, immunosuppression, and genetic susceptibility might produce a synergistic effect (6-9). The LSCC may evolve from lip premalignant conditions, as actinic cheilitis (AC), or even from the healthy lip. The time needed for sun-induced changes of the lip to evolve into cancer varies from 20 to 30 years, but such evolution can occur faster in some individuals (10). Although LSCC frequently occurs in a site of easy visualization by the patients themselves and health professionals, the average time of patient delay for malignant oral disease is somewhat late. This fact is justified by the fact that the disease is generally asymptomatic $(11,12)$. The LSCC shows survival rate higher than five years, exhibiting a better prognosis compared to the same disease in other sites of upper aerodigestive tract $(1,11$ 13).

The LSCC has great relevance with considerable incidences on tropical countries. Different epidemiological aspects of lip malignant disease seem to be strongly influenced by local socio-demographical and cultural factors. This background is important to ascertain the magnitude of the local and regional public health problem. The purpose of this study was to delineate the epidemiological profile of a LSCC Brazilian sample. Besides, we investigated associations between epidemiological and clinical factors of these patients.

\section{Patients and Methods}

\section{-Study design and ethical aspects}

This descriptive, cross-sectional study was performed analyzing a series of 30 fully reviewed cases of primary LSCC selected from 724 fully reviewed cases of primary upper aerodigestive tract squamous cell carcinoma (14), confirmed histologically. This sample was obtained from public and private health centers in north eastern of the Minas Gerais state, Brazil (latitude: $16^{\circ}$ 44' 06" - longitude: 43 51' 42') (Fig. 1), between 1996 and 2008. Epidemiological data (independent variables) were gathered from the medical and dentistry health records for this investigation and dichotomized as follows: age (young- the subjects who were aged 45 years or less and older), gender (female and male), anatomical site (lower and upper lip), ethnicity (white and non-white), cancer family history (absent and present), Karnofsky performance status scale - KPS (70-80 and 90-100), chronic solar exposure (exposed and non- exposed), and tobacco and alcohol drinking habits (absent and present). The clinical dependent variables of the study were: tumour size (T1/T2 - tumour less than $4 \mathrm{~cm}$ and T3/T4 - tumour higher than $4 \mathrm{~cm}$ ), cervical metastasis (absent and present), and clinical staging TNM (early-I/II and late-III/IV). The protocol for the majority of patients included surgical resection of the primary tumor associated with a conservative or radical neck dissection in cases of suspect cervical metastases as evidenced by clinical or imaginological exams. None of the patients examined presented distant metastases. Ethical approval was obtained from the relevant local ethics committees (Unimontes/COEP, protocol 1113/2008).

-Anatomical site, clinical staging, and morphological analysis

The anatomical sites reviewed in this study included: mouth and perioral region - lip (C00). All patients were staged according to the UICC TNM classification of Malignant Tumors (1997). LSCC was classified according to the primary site as described in the International Classification of Diseases (ICD-10) for Oncology (WHO, 1990). For the morphological analysis, it was used the WHO's grading system (squamous cell

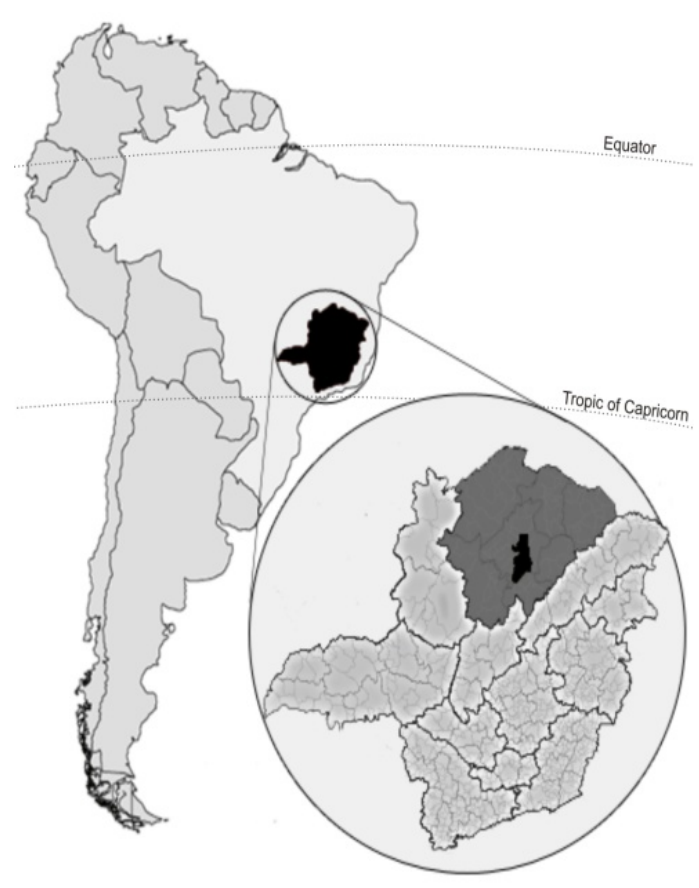

Fig. 1. Geographic localization of the research field. In detail, the black area represents the reference city for diagnosis, management, and treatment of oncologic disease. In it's around (darkest gray), the north region of the Minas Gerais state, Brazil. 
carcinoma samples classified into well, moderately and poorly differentiated) (15).

-Definitions of terms used for ethnicity, family cancer history, KPS, and tobacco and alcohol drinking habits Although ethnicity could not be truly established, respecting the findings about the hazards of judging Brazilians by colour, race and geographical origin (16), this variable was classified according to the skin colour of patients of this study. Cases considered as exposed to chronic solar exposure had cumulative and intense solar exposure in the workplace, such as farmers, construction employees, or garbage collectors. Non-exposure was the individual that did not report occupational antecedents of chronic solar exposition, such as teacher or dentist. All patients were asked about the occurrence of cancer in a first relative. The term cancer was defined using WHO definition as "an uncontrolled growth and spread of cells that may affect almost any tissue of the body". Performance status is a global assessment of the patients' actual level of function and ability of self-care. All the patients were categorized according to the Karnofsky performance status scale index (KPS) (17). It describes the ability of patients in in performing normal activities and doing active work, and whether there is any need for assistance of oncologic patients. The scale is rated $0-100$, in steps of 10 grades. At 100 all is well; at 0 the patient is dead. The drink habit (intake from overall alcohol, beer and cachaça, a very popular and inexpensive sugar cane spirit with 35-45\% ethyl alcohol content), was also investigated. A can of light beer (i.e. $330 \mathrm{ml}$ ) or a drink of cachaça (i.e. $40 \mathrm{ml}$ ) contains $12 \mathrm{~g}$ of ethanol. Alcohol drinking habit was classified as present or absent. In similar way, the tobacco habit was also investigated as present or absent. Ex-drinkers and ex-smokers were subjects who had abstained from any type of drinking and smoking for at least one year. Nonsmokers and ex-smokers were grouped combined. Similarly, with regard to alcohol intake, those patients that have never drunk alcohol were considered non-drinkers and were grouped with ex-drinkers.

-Statistical analyses

Descriptive statistics were calculated. Associations between epidemiological and clinical variables were examined by chi-square $\left(\mathrm{x}^{2}\right)$ and Fisher's exact tests. Statistical analysis showing a confidence above $95 \%$ $(p<0.05)$ were considered significant. All tests for significance were two-sided. All statistical analyses were performed with the statistical pack SPSS ${ }^{\circledR}$ (SPSS Inc., Chicago, IL, USA), version 13.0 for Windows ${ }^{\circledR}$.

\section{Results}

The descriptive statistics of LSCC group is presented in table 1 . The LSCC lesions represented $10.8 \%$ of all oral cavity squamous cell carcinomas and perioral region and $3.5 \%$ of total cases with localization in the upper aerodigestive tract. The LSCC involved mainly the lower lip (83.3\%). The male-to-female ratio was 5:1, with a mean age at the diagnosis of $58.8( \pm 15.57)$ years, ranging from 25 to 92 years). The majority of individuals were represented by older patients (76.7\%). Age parameter among female gender varied from 56 to 86 years (mean 67.6 years), and in the male group it varied from 25 to 92 years (mean 57.1 years). It was noted significant association between chronic solar exposure in the job's environment and incidence of LSCC in lower lip $(p=0.019)$ (data not shown). Half of LSCC patients were evaluated as capable in performing normal activities according to KPS index.

Associations between epidemiological and clinical factors are presented in table 2. The occurrence of cervical metastasis was statistically associated with worse KPS scores $(p=0.035)$. Finally, it was observed a significant association between T3/T4 lesions and LSCC samples with loss of morphological differentiation $(\mathrm{p}=0.023)$ (data not shown).

\section{Discussion}

Lip squamous cell carcinoma is an important public health problem in many countries around the world $(2,6,11-13)$. However, according to regional context, it is important to realize the influence of specific environmental risk factors in which individuals have been exposed. The LSCC has its origin related mainly to chronic solar exposure $(3,5)$. Additionally, it has been shown that occupational antecedents provided us a good idea of sun exposition grade (18). In the current study, we found an association between chronic solar exposure in the workplace and incidence of LSCC. The region investigated in this current study assumes importance to the LSCC because of high solar radiation level, typical of tropical regions. Besides, this region maintains its economy based on agriculture activities, and therefore, many people usually work subjected to long periods under sun radiation exposure (19). Regarding the typical socio-demographic profile of LSCC patients, probably the typical lack of information about the etiology of lip cancer has contributed for most intensive exposure to its risk factors.

In our study, nearly all cases of LSCC were located in lower lip. The higher occurrence of lip disease in this anatomical site has been attributed to its position, which usually receives a higher exposure of solar radiation (6). Still, it is probable that tobacco and alcohol beverage products might also act more frequently for occurrence of disease in lower lip. Interestingly, it has been suggested that the etiology of upper lip cancer could be regarded as a separate entity and different from the lower lip (5). Women, as noted in other studies, were less affected by disease than men (12). This finding has been associated with the frequent use of lipstick, a known 
Table 1. Descriptive analysis of socio-demographic, clinical, and morphological variables of the LSCC patients of this study.

\begin{tabular}{|c|c|c|c|c|c|}
\hline Variables & $\mathrm{n}$ & $\%$ & Variables & $\mathrm{n}$ & $\%$ \\
\hline$\underline{\text { Gender }}$ & & & $\underline{\text { Age }}$ & & \\
\hline Male & 25 & 83.3 & Young & 07 & 23.3 \\
\hline Female & 05 & 16.7 & Older & 23 & 76.7 \\
\hline$\underline{\text { Skin color }}$ & & & $\underline{\text { Chronic Solar Exposure }}$ & & \\
\hline White & 13 & 43.3 & Exposed & 21 & 70.0 \\
\hline Non-white & 17 & 56.7 & Non-exposed & 09 & 30.0 \\
\hline Family History of Cancer & & & $\underline{\mathrm{KPS}}$ & & \\
\hline Absent & 20 & 66.7 & $90-100$ & 15 & 50.0 \\
\hline Present & 10 & 33.3 & $70-80$ & 15 & 50.0 \\
\hline Tobacco Use & & & Alcohol Drinking Use & & \\
\hline Never & 06 & 20.0 & Never & 12 & 40.0 \\
\hline Ever & 24 & 80.0 & Ever & 18 & 60.0 \\
\hline$\underline{\text { Tumor Site }}$ & & & $\underline{\text { Tumor Size }}$ & & \\
\hline Upper lip & 05 & 16.7 & $\mathrm{~T} 1 / \mathrm{T} 2$ & 23 & 76.7 \\
\hline Lower lip & 25 & 83.3 & $\mathrm{~T} 3 / \mathrm{T} 4$ & 07 & 23.3 \\
\hline$\underline{\text { Cervical Metastasis }}$ & & & $\underline{\text { TNM Staging }}$ & & \\
\hline Absent & 22 & 73.3 & Early & 23 & 76.7 \\
\hline Present & 08 & 26.7 & Late & 07 & 23.3 \\
\hline \multicolumn{6}{|l|}{ WHO Grading } \\
\hline Well Differentiated & 17 & 56.7 & & & \\
\hline Moderately Differentiated & 06 & 20.0 & & & \\
\hline Poorly Differentiated & 07 & 23.3 & & & \\
\hline
\end{tabular}

Table 2. Association between the epidemiological and clinicopathological variables of LSCC sample.

\begin{tabular}{|c|c|c|c|c|c|c|c|c|c|c|c|c|c|}
\hline \multirow[b]{2}{*}{ Variable } & \multicolumn{2}{|c|}{ Size Tumor } & \multicolumn{4}{|c|}{$\begin{array}{c}\text { Cervical Metastasis } \\
\end{array}$} & \multicolumn{3}{|c|}{ TNM Staging } & \multicolumn{4}{|c|}{ WHO Grading } \\
\hline & $\mathrm{T} 1 / \mathrm{T} 2$ & $\mathrm{~T} 3 / \mathrm{T} 4$ & $\mathrm{p}$ value & Absent & Present & $\mathrm{p}$ value & Early & Late & $\mathrm{p}$ value & Well & Moderate & Poorly & $\mathrm{p}$ value \\
\hline$\underline{\text { KPS }}$ & & & & & & & & & & & & & \\
\hline $90-100$ & $\begin{array}{c}14 \\
(60.9)\end{array}$ & $\begin{array}{c}01 \\
(14.3)\end{array}$ & 0.080 & $\begin{array}{c}14 \\
(63.6)\end{array}$ & $\begin{array}{c}01 \\
(12.5)\end{array}$ & $0.035^{*}$ & $\begin{array}{c}13 \\
(61.9)\end{array}$ & $\begin{array}{c}02 \\
(22.2)\end{array}$ & 0.109 & $\begin{array}{c}11 \\
(64.7)\end{array}$ & $\begin{array}{c}0.2 \\
(33.3)\end{array}$ & $\begin{array}{c}0.2 \\
(28.6)\end{array}$ & 0.181 \\
\hline $70-80$ & $\begin{array}{c}09 \\
(39.1)\end{array}$ & $\begin{array}{c}06 \\
(85.7)\end{array}$ & & $\begin{array}{c}0.8 \\
(36.4)\end{array}$ & $\begin{array}{c}0.7 \\
(87.5)\end{array}$ & & $\begin{array}{c}08 \\
(38.1)\end{array}$ & $\begin{array}{c}07 \\
(77.8)\end{array}$ & & $\begin{array}{c}0.6 \\
(35.3)\end{array}$ & $\begin{array}{c}0.4 \\
(66.7)\end{array}$ & $\begin{array}{c}0.5 \\
(71.4)\end{array}$ & \\
\hline
\end{tabular}

Values calculated by $\mathrm{x}^{2}$ and exact Fisher statistical tests.

$* \mathrm{p}$ value significant $(\mathrm{p}<0.05)$. 
lip protector against solar exposure $(1,6)$. The high ratio male:female could be attributed to the fact that most outdoor workers are men. However, nowadays, women have been exposed to sunlight as often as males due to their similar working habits.

Currently, it has been noted evidences that display the association between tobacco and alcohol drinking habits and the occurrence of squamous cell carcinoma in the upper aerodigestive tract $(8,16)$, including LSCC (1-4). Although the occurrence of tobacco and alcohol drinking habits were significant in our sample, these findings seem to be more important for early events of lip carcinogenesis instead of influencing the clinical factors of lip malignant disease. Future studies are needed to clarify the potential contribution of tobacco and alcohol consumption to the LSCC etiopathogenesis.

The hypothesis that cancer may be a time-dependent process (20) is consistent with the findings of our study, mainly considering the similar time of exposure to the risk factors investigated in this current study for both the young and older patients (data not shown). As the cancer family history was not an important factor influencing the clinical factors of LSCC in this study ( $p$ $=0.542$; data not shown), it seems that environmental factors and its cumulative levels were more critical for the onset of lip malignant disease. In some cases, the hereditary characteristic of the LSCC has been suggested associated in particular with common family risk factors (21).

Our results showed that LSCC patients frequently exhibited, at the diagnosis moment, early TNM clinical staging and absence of cervical metastasis. Lip is easily accessed clinically compared to other sites of oral cavity. The literature shows that LSCC is associated with the lowest incidence of cervical metastasis among all the cancers of the oral cavity, especially when referring to small lesions $(22,23)$. The occurrence of disease in this site usually stimulates an early search for health care centers, especially for aesthetic reasons (23).

Reduced global health has been found in cancer patients (24-26). The KPS has been used as a guide to treatment plans for individual oncologic patients by clinicians because of its association with prognosis (25). In this study, it was shown that the occurrence of cervical metastasis was associated with KPS scores $\leq 80$. This finding emphasizes the importance of health state and the need of adequate care for the patients. As frequently noted, TNM staging exhibits powerful impact on prognosis of oral squamous cell carcinoma patients $(26,27)$. The association between lower KPS scores and cervical metastasis seems to be related to duration of disease and it might potentially contribute to a worse prognosis of the LSCC. Further studies are necessary in order to clarify the causal inferences of this association.

This current study has presented limitations, such as sample size, especially for statistical reasons. Besides, the typical difficulties of cross-sectional study design in to establish causal inference. Our findings showed that LSCC patients exhibited typical epidemiological and clinical profiles as noted in other studies. These findings can be useful for stimulating the creation of health promotion strategies, particularly in Brazil where the Family Health Strategy represents the main government strategy to improve primary health care in the communities. Additionally, the occurrence of metastatic disease was associated with a worse physical status of the LSCC patients during diagnosis. This association needs to be better elucidated in future studies.

\section{References}

\section{References with links to Crossref - DOI}

1. Main JH, Pavone M. Actinic cheilitis and carcinoma of the lip. J Can Dent Assoc. 1994;60:113-6.

2. Sugerman PB, Savage NW. Oral cancer in Australia: 1983-1996. Aust Dent J. 2002;47:45-56.

3. Anderson DL. Cause and prevention of lip cancer. J Can Dent Assoc (Tor). 1971;37:138-42.

4. De Visscher JG, Van der Waal I. Etiology of cancer of the lip. A review. Int J Oral Maxillofac Surg. 1998;27:199-203.

5. Lindqvist C, Teppo L. Epidemiological evaluation of sunlight as a risk factor of lip cancer. Br J Cancer. 1978;37:983-9.

6. Luna-Ortiz K, Güemes-Meza A, Villavicencio-Valencia V, Mosqueda-Taylor A. Lip cancer experience in Mexico. An 11-year retrospective study. Oral Oncol. 2004;40:992-9.

7. García-Montesinos-Perea B, Val-Bernal JF, Saiz-Bustillo R. Epidermoid carcinoma of the lip: an immunohistochemical study. Med Oral Patol Oral Cir Bucal. 2005;10:454-61.

8. Figuero Ruiz E, Carretero Peláez MA, Cerero Lapiedra R, Esparza Gómez G, Moreno López LA. Effects of the consumption of alcohol in the oral cavity: relationship with oral cancer. Med Oral. 2004;9:14-23.

9. Van Leeuwen MT, Grulich AE, McDonald SP, McCredie MR, Amin J, Stewart JH, et al. Immunosuppression and other risk factors for lip cancer after kidney transplantation. Cancer Epidemiol Biomarkers Prev. 2009;18:561-9.

10. Cataldo E, Doku HC. Solar cheilitis. J Dermatol Surg Oncol. 1981;7:989-95.

11. Jovanovic A, Schulten EA, Kostense PJ, Snow GB, Van der Waal I. Squamous cell carcinoma of the lip and oral cavity in The Netherlands; an epidemiological study of 740 patients. J Craniomaxillofac Surg. 1993;21:149-52.

12. Vukadinovic M, Jezdic Z, Petrovic M, Medenica LM, Lens M. Surgical management of squamous cell carcinoma of the lip: analysis of a 10-year experience in 223 patients. J Oral Maxillofac Surg. 2007;65:675-9.

13. Antoniades DZ, Styanidis K, Papanayotou P, Trigonidis G. Squamous cell carcinoma of the lips in a northern Greek population. Evaluation of prognostic factors on 5-year survival rate--I. Eur J Cancer B Oral Oncol. 1995;31B:333-9.

14. De Paula AM, Souza LR, Farias LC, Corrêa GT, Fraga CA, Eleutério NB, et al. Analysis of 724 cases of primary head and neck squamous cell carcinoma (HNSCC) with a focus on young patients and p53 immunolocalization. Oral Oncol. 2009;45:777-82.

15. Roland NJ, Caslin AW, Nash J, Stell PM. Value of grading squamous cell carcinoma of the head and neck. Head Neck. 1992;14:224-9.

16. Parra FC, Amado RC, Lambertucci JR, Rocha J, Antunes CM, Pena SD. Color and genomic ancestry in Brazilians. Proc Natl Acad Sci U S A. 2003;100:177-82.

17. Karnofsky DA. Chemotherapy of neoplastic disease; agents of clinical value. N Engl J Med. 1948;239:299-305.

18. Efird JT, Friedman GD, Habel L, Tekawa IS, Nelson LM. Risk of 
subsequent cancer following invasive or in situ squamous cell skin cancer. Ann Epidemiol. 2002;12:469-75.

19. Rigotto RM, Augusto LG. [Health and environment in Brazil: development, territory, and social iniquity]. Cad Saude Publica. 2007;23 Suppl 4:S475-85.

20. Miller RA. Gerontology as oncology. Research on aging as the key to the understanding of cancer. Cancer. 1991;68:2496-501.

21. Cannon-Albright LA, Thomas A, Goldgar DE, Gholami K, Rowe $\mathrm{K}$, Jacobsen M, et al. Familiality of cancer in Utah. Cancer Res. 1994;54:2378-85

22. Vartanian JG, Carvalho AL, de Araújo Filho MJ, Junior MH, Magrin J, Kowalski LP. Predictive factors and distribution of lymph node metastasis in lip cancer patients and their implications on the treatment of the neck. Oral Oncol. 2004;40:223-7.

23. Zitsch RP 3rd, Lee BW, Smith RB. Cervical lymph node metastases and squamous cell carcinoma of the lip. Head Neck. 1999:21:447-53.

24. Fang FM, Liu YT, Tang Y, Wang CJ, Ko SF. Quality of life as a survival predictor for patients with advanced head and neck carcinoma treated with radiotherapy. Cancer. 2004;100:425-32.

25. Schag CC, Heinrich RL, Ganz PA. Karnofsky performance status revisited: reliability, validity, and guidelines. J Clin Oncol. 1984;2:187-93.

26. Hammerlid E, Bjordal K, Ahlner-Elmqvist M, Boysen M, Evensen JF, Biörklund A, et al. A prospective study of quality of life in head and neck cancer patients. Part I: at diagnosis. Laryngoscope. 2001;111:669-80.

27. Scully C, Bagan J. Oral squamous cell carcinoma overview. Oral Oncol. 2009;45:301-8.

\section{Acknowledgments}

This study was supported by Foundation for the Support of Research of Minas Gerais State (Fapemig). 